\title{
Trends in Tobacco Smoking in Pregnant Women: Data From French National Perinatal Surveys
}

\author{
Virginie Demiguel ${ }^{1 *}$, Béatrice Blondel ${ }^{2,3}$, Camille Bonnet ${ }^{2,3}$, Viêt Nguyen-Thanh ${ }^{1}$, \\ Marie-Josèphe Saurel-Cubizolles ${ }^{2,3}$ and Nolwenn Regnault ${ }^{1}$
}

${ }^{1}$ Santé Publique France, French National Public Health Agency, Saint-Maurice, France, ${ }^{2}$ Université de Paris, CRESS, INSERM, INRA, Paris, France, ${ }^{3}$ INSERM U1153, Obstetrical, Perinatal and Paediatric Epidemiology Research Team (Epopé), Paris, France

Objectives: To describe maternal smoking trends in France between 1972 and 2016, and identify whether maternal characteristics associated with smoking in the 3rd trimester of pregnancy evolved between 2010 and 2016.

Methods: Using French National Perinatal Surveys, we estimated proportions of smokers and the number of cigarettes smoked both just before pregnancy and during the 3rd trimester from 1972 to 2016 . We used a Poisson model with robust variance to estimate prevalence ratios for smoking during pregnancy.

Results: Proportions of mothers quitting smoking were relatively stable (46.0\% in 1972 and $45.8 \%$ in 2016). The number of cigarettes smoked just before pregnancy and in the 3rd trimester decreased from 1995 onward. However, proportions of smokers remained high before (30.1\%) and during the 3rd trimester in 2016 (16.2\%). Smoking in the 3rd trimester was associated with a lower education level and lower income in both 2010 and 2016, whereas the association with age, country of birth and parity varied according to the survey year.

OPEN ACCESS

Edited by:

Katherine Frohlich,

Université de Montréal, Canada

*Correspondence:

Virginie Demiguel

Virginie.demigue/@

santepubliquefrance.fr

Received: 04 September 2020 Accepted: 11 February 2021

Published: 01 April 2021

Citation:

Demiguel V, Blondel B, Bonnet C, Nguyen-Thanh V, Saurel-Cubizolles M-J

and Regnault N (2021) Trends in

Tobacco Smoking in Pregnant Women:

Data From French National

Perinatal Surveys.

Int J Public Health 66:602873.

doi: 10.3389/ijph.2021.602873
Conclusion: Early targeted interventions are needed for smokers who plan to have a child and must take smokers' characteristics during pregnancy into account.

Keywords: smoking cessation, surveillance, trends, pregnancy, tobacco smoking

\section{INTRODUCTION}

Tobacco smoking in women is a serious public health problem in Europe, with a prevalence well above the average in developed countries [1]. France has one of the highest prevalences of smoking in Europe both for women of childbearing age [2] and pregnant women [3]. Smoking prevalence in France remained stable between 2010 and 2016 in women aged 25-44 (with just over one-third smoking tobacco on a daily basis) $[4,5]$.

In the most recently published national data available on smoking during pregnancy in France, $20.8 \%$ of women declared smoking during the 3 rd trimester in 2003 . Only $41.8 \%$ reported quitting smoking during pregnancy [6], despite the French National Authority for Health's (Haute Autorité de Santé) recommendation not to smoke during this period (www.has-sante.fr). Reported proportion of women quitting smoking during pregnancy differ according to region, and range from $25 \%$ in Australia to over $50 \%$ in the United States $[7,8]$. 
The harmful effects of smoking during pregnancy on the health of both the mother and the child are well documented. For the former, the risk of developing any one of a large number of associated diseases and pregnancy-related complications (ectopic pregnancy, miscarriage, placenta praevia, etc.) is increased [9]. For the latter, intrauterine growth retardation, preterm delivery and fetal death have all been documented, as well as increased risk of unexpected sudden death $[9,10]$. In children and young adults, reduced educational and cognitive abilities [9, 11] and behavioral problems [12] have also been suggested as maternal smoking-related consequences.

Most of the risk factors associated with smoking during pregnancy are well known. These include younger age, a low socioeconomic status, already having children, not living with a partner, and unemployment status [13, 14]. Previous studies have also reported different smoking trends during pregnancy according to sociodemographic groups $[15,16]$. This suggests the need for continuous health surveillance of women at greatest risk of prenatal smoking in order to better inform public health policy makers and adjust current smoking cessation interventions. Using data from all six French National Perinatal Surveys (NPS) conducted to date, we aimed to describe temporal trends in smoking prevalence, in the proportions of mothers quitting smoking, and in the number of cigarettes smoked by women just before and during pregnancy, between 1972 and 2016. Our secondary objective was to describe the evolution of the characteristics of women who reported smoking in the 3rd trimester of pregnancy over 2010-2016, as we suppose that the most recent data available are the most relevant to inform future prevention and intervention plans.

\section{METHODS}

\section{Study Design}

The NPS are designed to collect information about the health status of mothers and their newborns, perinatal care, maternal behaviour, and risk factors from a representative sample of births. To date six have been conducted: in 1972, 1981, 1995, 2003, 2010, and 2016. All methodological details and study population characteristics have been described elsewhere [5, 17-19].

Briefly, the first two surveys (1972 and 1981) used the same protocol: mainland France was split into 12 zones, the survey taking place each month in a different zone with a sampling fraction twice as small in 1981 as that in 1972. From 1995 onward, the sampling plan was simplified, with the survey being conducted over one week in all public and private maternity units in France. Maternity coverage in all surveys was close to $100 \%$ [5].

\section{NPS Data Collection}

Data collection covered all live births and stillbirths with a gestational age of at least 22 weeks or a birth weight of at least $500 \mathrm{~g}$ in public and private maternity units. An information letter, describing the objectives and implementation modalities of the survey, was given to women following childbirth by the midwife survey investigator. For those who agreed to participate, data were collected both in a face-to-face interview with another investigator before their discharge, and/or from their medical record. The participation rate was approximately $90 \%$ and for most women, data came from both these sources. The interview collected data on sociodemographic characteristics, behaviours just before and during pregnancy-especially maternal smoking-as well as prenatal care. The medical data included information on maternal medical history, delivery and potential adverse outcomes for the newborn.

\section{Study Sample Size}

For the present analyses, the same criteria were used to select the women to include from each NPS (1972-2016) to ensure comparability of indicators over time. Specifically, we included adult women ( $\geq 18$ years) who gave birth to a live child in mainland France. Furthermore, women who did not answer questions about tobacco use in the NPS (ranging between a minimum of $3.3 \%$ in 1972 and a maximum of $9.6 \%$ in 2016) were not included in our analyses. Most of these women did not have a face-to-face interview, either because they or their newborn child were in poor health, or because of language difficulties. Accordingly, analyses were based on a sample of 10,474 women in $1972,5,173$ in $1981,12,219$ in $1995,13,060$ in $2003,13,933$ in 2010 , and 11,733 in 2016 . The size of these samples was sufficient to precisely estimate indicators with a prevalence of at least $10 \%$ and to analyse factors related to these indicators. We were granted access to aggregated data for 1972-2003 and individual data for 2010 and 2016 (Supplementary Table S1).

\section{Variables Studied}

Variables Relating to Mothers' Tobacco Consumption In each NPS, participants retrospectively reported the average number of cigarettes they smoked per day just before pregnancy and during the $3 \mathrm{rd}$ trimester. Five categories were created, based on the size of commercial packs of cigarettes: no cigarette, 1-4 cigarettes per day, 5-9 cigarettes, $10-19$ cigarettes (or $1 / 2$ a pack or more), $\geq 20$ cigarettes (or 1 or more packs).

For the most recent years-2010 and 2016-we identified three patterns by comparing the numbers of cigarettes smoked per day just before pregnancy with the number smoked during the 3rd trimester: 1/women who quit smoking during pregnancy (i.e., smoking just before pregnancy but not in the 3rd trimester), 2/women who reduced their consumption during pregnancy, and 3/women who did not reduce or have increased their consumption during pregnancy.

\section{Sociodemographic Variables}

The following characteristics were studied for both 2010 and 2016: maternal age, country of birth (France, outside France), marital status (living with a partner, single), parity at the time of pregnancy (nulliparous, 1, 2, or $\geq 3$ ), educational level (none/ primary/middle school, high school, 1-2 years of tertiary education, 3-4 years or $\geq 5$ years of tertiary education), employment status at end of pregnancy (employed, unemployed, housewife, other), average monthly household income (in euros) and type of social health insurance cover at 


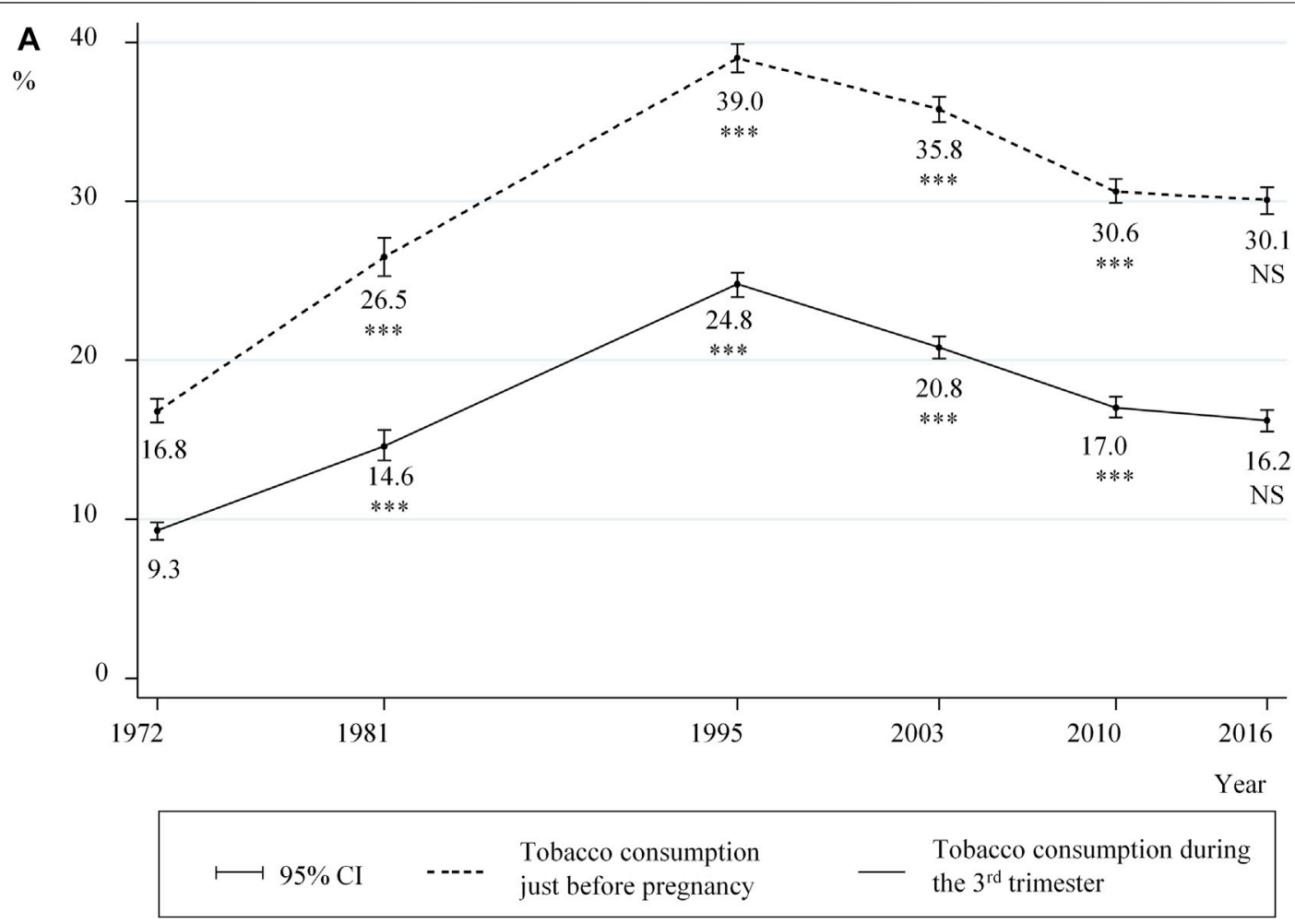

B

\begin{tabular}{lcccccc}
\hline Survey year & 1972 & 1981 & 1995 & 2003 & 2010 & 2016 \\
\hline Sample size (N) & 10,474 & 5173 & 12,219 & 13,060 & 13,933 & 11,733 \\
& & & & & & \\
\hline $\begin{array}{l}\text { Smoking just before } \\
\text { pregnancy (n) }\end{array}$ & 1760 & 1370 & 4603 & 4665 & 4243 & 3526 \\
\hline $\begin{array}{l}\text { Smoking cessation (\%); } \\
\text { 95\% CI }\end{array}$ & 46.0 & 45.2 & 36.7 & 42.1 & 42.7 & 45.8 \\
p-value & {$[43.7-48.3]$} & {$[42.6-47.8]$} & {$[35.3-38.1]$} & {$[40.7-43.5]$} & {$[41.2-44.2]$} & {$[44.1-47.4]$} \\
\hline
\end{tabular}

FIGURE 1 | Smoking prevalence before and during pregnancy, and proportions of cessation between 1972 and 2016 (A) Smoking prevalence just before pregnancy and during the 3rd trimester (B) proportions of smoking cessation; prevalences for two consecutive surveys were compared using Pearson's Chi-square test (A) and (B): $95 \% \mathrm{Cl}$ : 95\% confidence intervals; ${ }^{\star \star *}$ for $p$-value<0.01 and NS: not significant (B) ${ }^{2}$ Among smokers just before pregnancy (data from the National Perinatal Surveys from 1972 to 2016 , France).

the beginning of pregnancy (general social security cover, other cover (e.g., assistance for undocumented migrants).

\section{Statistical Analysis}

For the first objective, to account for the time trends in tobacco consumption in pregnant women between 1972 and 2016, three indicators were estimated: smoking prevalence just before pregnancy, prevalence during the 3rd trimester, and, the distribution of smokers according to the number of cigarettes smoked per day just before pregnancy and during the 3rd trimester. For these indicators, comparisons between each two consecutive survey year were tested using Pearson's Chi-square test (with a p-value $<0.01$ to account for multiple comparisons). For recent years only (2010 and 2016), we also estimated the proportions of smokers who quit, who reduced or who did not reduce/have increased their consumption during pregnancy as a function of their consumption before pregnancy.

For the secondary objective, a Poisson model with robust variance [20] was used to estimate the crude and adjusted 
prevalence ratios (PR) of smoking in the 3rd trimester of pregnancy and their 95\% confidence intervals. This model allowed us to test for the effect of the year on the prevalence of smoking during the 3rd trimester, adjusted for relevant maternal characteristics. All included covariates were categorical variables with the exception of age. For the latter, we used the fractional polynomial method to model the link function of the relationship between maternal age and the prevalence of smoking in the 3rd trimester. Accordingly, maternal age was included as a linear function (as the likelihood ratio test was not significant). To test whether the association of each covariate with the prevalence of smoking in the 3rd trimester changed between 2010 and 2016, an interaction term between the covariate and the study year was introduced into the model. Given the significant interactions observed, we decided to present the results separately for 2010 and 2016.

The analyses were performed using Stata 13.1 software (College Station, Texas 77845 United States).

\section{RESULTS}

Participants in the 2016 NPS were on average 30.3 years old. Most were born in France (81.4\%) and lived with a partner (91.6\%). Over half were multiparous at the time of pregnancy (57.6\%), and had an education level $>$ high school (55.5\%). At the end of their pregnancy, two-thirds reported being employed (68.2\%) (Supplementary Table S1).

\section{Tobacco Consumption Prevalence Before and During Pregnancy}

In 2016, 30.1 and $16.2 \%$ of the NPS participants declared smoking just before pregnancy and in the 3rd trimester, respectively. Although a steady decline in tobacco consumption prevalence during pregnancy was observed from 1995 onward, the difference between 2010 and 2016 was not significant $(p=0.08)$ (Figure 1), even when taking maternal characteristics into account (data not shown). Among women who smoked just before pregnancy, the proportion of those who quit in the 3rd trimester varied little throughout the entire study period (i.e., 1972-2016) (Figure 1).

\section{Number of Cigarettes Smoked Before and During the 3rd Trimester}

After an increase in the number of cigarettes smoked daily between 1972 and 1995, lower consumption before pregnancy (Figure 2) and during the 3rd trimester (Figure 3) was observed from 1995 onward. More specifically, the proportion of women smoking an average of $\geq 20$ cigarettes per day in the 3 rd trimester decreased from $11.4 \%$ in 1995 to $4.2 \%$ in 2016 , while those smoking an average of 5-9 cigarettes a day increased from 29.6 to $38.3 \%$. However, these proportions remained stable in the last two surveys 2010 and 2016 (Figure 3).

\section{Evolution of Tobacco Consumption During Pregnancy as a Function of Consumption just Before Pregnancy}

In 2016, $45.8 \%$ of women who smoked before pregnancy quit during pregnancy. Nevertheless, the proportion of women quitting smoking varied with the amount of tobacco consumed before pregnancy $(p<0.001)$. More specifically, women who smoked 1-4 cigarettes a day before pregnancy in 2016 were much more likely to quit during pregnancy than those who smoked $\geq 20$ cigarettes/day (82.3 vs. 19.5\%) (Figure 4).

In $2016,44.9 \%$ of women who smoked during pregnancy reduced their tobacco consumption compared with their prepregnancy consumption (vs. $46.3 \%$ in $2010, p=0.21$ ). Of these, 84.8 and $83.1 \%$ reduced their consumption by at least $50 \%$ in 2010 and 2016, respectively (data not shown). Nevertheless, for both years, the proportion of women reducing their consumption was significantly associated with pre-pregnancy tobacco consumption levels. More specifically, women who previously smoked $\geq 20$ cigarettes a day were ten times more likely to reduce consumption than those who smoked 1-4 cigarettes a day (74.0 vs. 7.4\%, respectively). A similar pattern was observed for 2010 (Figure 4). In 2016, only $9.3 \%$ of smokers did not decrease their consumption during pregnancy (10.8\% in 2010 , data not shown).

\section{Evolution of Characteristics Associated with Tobacco Consumption in the 3rd Trimester of Pregnancy}

The proportions of smokers are presented according to mothers' sociodemographic characteristics for each survey year (Table 1).

In 2010 and 2016, the prevalence of smoking in the 3rd trimester was higher in women who lived alone and those not living with their partner. Furthermore, the lower the education and income levels, the higher the prevalence of smoking in the 3rd trimester. These associations did not change between 2010 and 2016 (non-significant interaction tests) (Table 2).

Interaction tests showed that the association between tobacco consumption in the $3 \mathrm{rd}$ trimester and maternal characteristics differed according to survey year for age $(p=0.003)$, parity $(p=$ $0.004)$ and country of birth $(p=0.04)$. More specifically, while the prevalence of smoking was not associated with age in 2010, a $6 \%$ higher prevalence ratio was observed for each 5 years age increment in 2016. Furthermore, the higher prevalence of smoking in the 3rd trimester in women with three or more children in 2010 (PR $=1.38,95 \%$ CI [1.20-1.59]) was no longer significant in 2016.

The relatively higher prevalence of smoking during pregnancy in women born in France (compared with those born elsewhere) observed in 2010 was also found in 2016, albeit to a lesser degree $(\mathrm{PR}=4.57,95 \% \mathrm{CI}$ [3.79-5.52] in 2010 versus. $3.47,95 \% \mathrm{CI}$ [2.89-4.17] in 2016). More specifically, while the prevalence ratio of smoking during pregnancy in 2016 was lower than in 2010 in women born in France (PR $=0.64,95 \%$ CI [0.47-0.87]), it tended to increase slightly in women born elsewhere $(\mathrm{PR}=1.17,95 \% \mathrm{CI}$ [0.91-1.50]) (data not shown). 


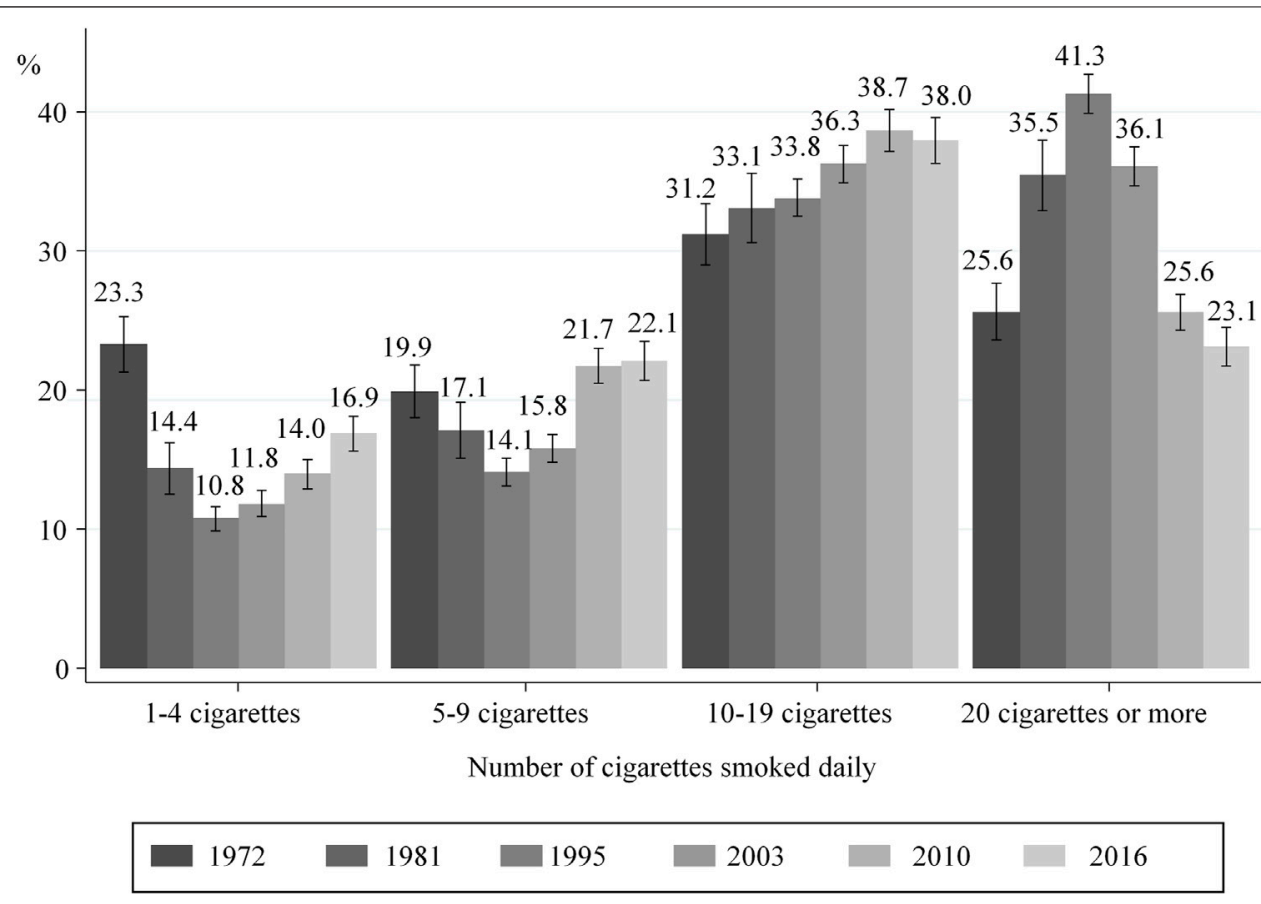

FIGURE 2 | Distribution of smokers according to the number of cigarettes smoked daily just before pregnancy; with 95\% confidence intervals (data from National Perinatal Surveys from 1972 to 2016, France).

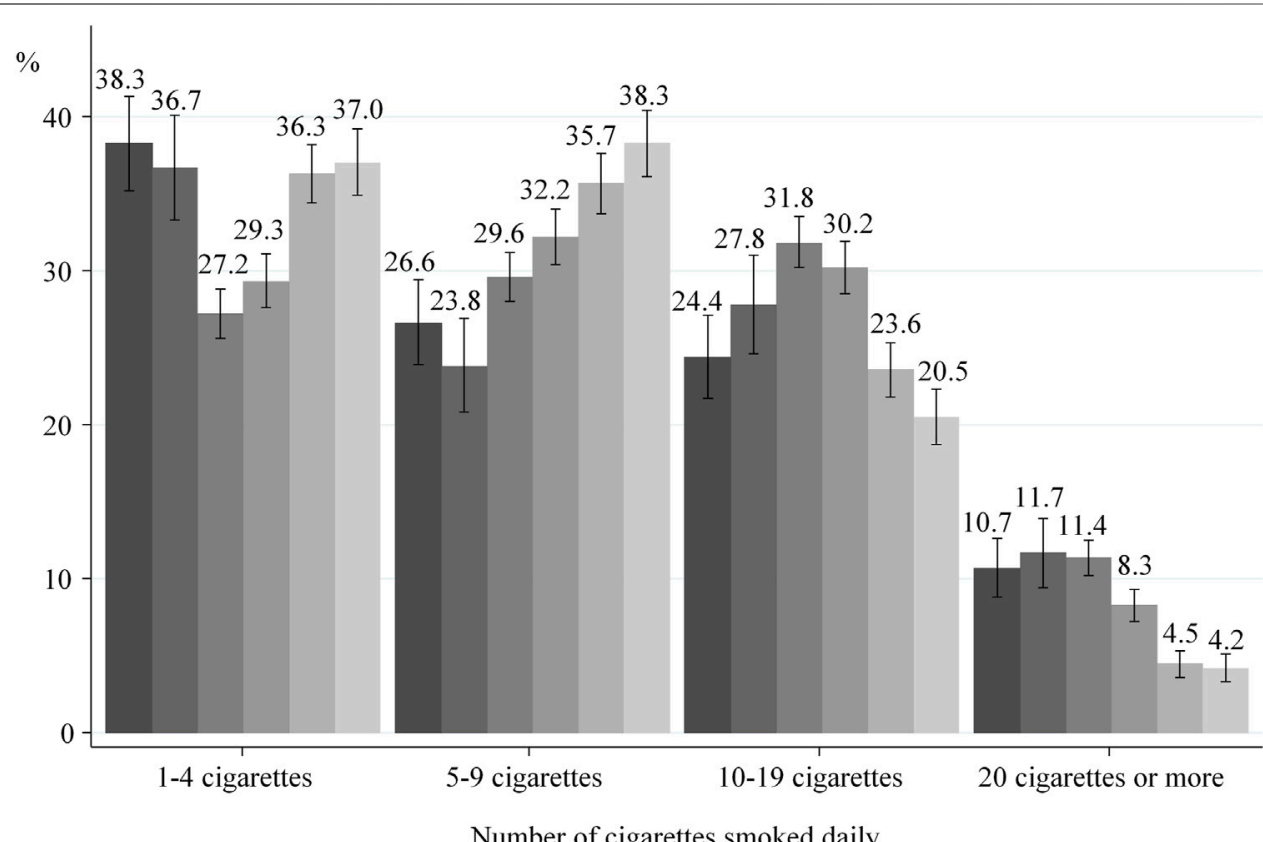

Number of cigarettes smoked daily

FIGURE 3 | Distribution of smokers according to the number of cigarettes smoked daily in the 3rd trimester of pregnancy; with 95\% confidence intervals (data from the National Perinatal Surveys from 1972 to 2016, France). 


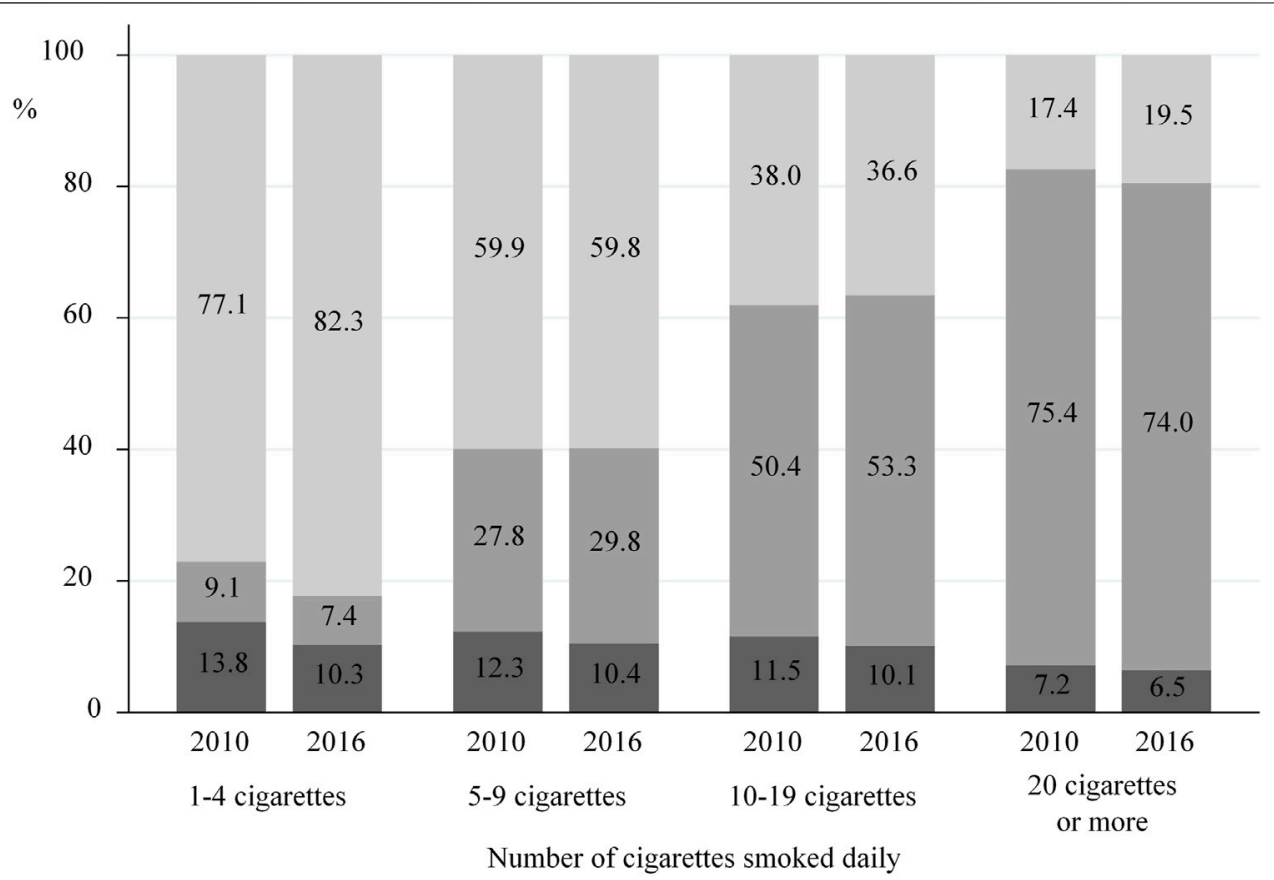

\begin{tabular}{l|l|l} 
No change & $\begin{array}{l}\text { Reduction in tobacco } \\
\text { consumption }\end{array}$ & Smoking cessation \\
or increase & Sm
\end{tabular}

FIGURE 4 | Change between 2010 and 2016 in smoking behaviours (Cessation, reduction, no change) during pregnancy with respect to tobacco consumption smoked just before pregnancy (data from the National Perinatal Surveys in 2010 and 2016, France).

\section{DISCUSSION}

\section{Principal Findings}

Our study shows that between 1995 and 2010, tobacco consumption in women living in France both before and during pregnancy decreased, while proportions tended to stabilize between 2010 and 2016. The proportions of mothers quitting smoking were remarkably constant between 1972 and 2016 with approximately $45 \%$ of women quitting smoking during pregnancy. Between 1995 and 2016, the amount of tobacco consumed during pregnancy decreased for those who continued to smoke while pregnant. The prevalence of smoking in the 3rd trimester was higher in women with less favourable socioeconomic characteristics in both 2010 and 2016. In contrast, the association between smoking in the 3rd trimester and age, country of birth and parity differed between both these years.

\section{Stabilization of smoking prevalence and of the number of cigarettes smoked daily by women living in France before and during pregnancy between 2010 and 2016}

Public health measures implemented between 2010 and 2016 in France (increases in the prices of packets of cigarettes, visual health messages on packets, flat-rate annual reimbursement for nicotine replacement treatments (NRT)) had little effect on reducing smoking prevalence and daily tobacco consumption before and during pregnancy over this period. However, complementary measures introduced in 2015-2016-including a pictogram advocating the non-consumption of tobacco during pregnancy on all tobacco products, the total reimbursement of NRT for pregnant women and their close family, plain packaging, ambitious social marketing campaigns and price increases on packets of cigarettes (10 euros by the end of 2020) - may prove to have a greater influence on reducing smoking prevalence in women who are or wish to become pregnant.

\section{Higher Probability of Quitting Among Light Smokers}

Our results show that the probability of quitting during pregnancy was higher when consumption just before pregnancy was low, reflecting findings elsewhere [21]. In addition, heavy smokers tended to reduce the number of cigarettes they smoked daily more than light smokers. This raises questions about the contents of anti-smoking messages and the level of support provided for quitting, especially from healthcare professionals. In the 2016 NPS, $79.9 \%$ of women reported that they had been interviewed by a healthcare professional about their tobacco consumption during pregnancy. Furthermore, only $46.3 \%$ of those who reported smoking during pregnancy declared receiving counseling for quitting [5]. It is possible that healthcare providers find it difficult to convince and help women to quit. Indeed, French general practitioners are more inclined to advise their pregnant patients to reduce their 
TABLE 1 | Maternal characteristics associated with smoking in the 3rd trimester of pregnancy in 2010 and 2016 (univariate analysis). Data from the National Perinatal Surveys in $2010(\mathrm{~N}=13,777)$ and $2016(\mathrm{~N}=11,704)$, France.

\begin{tabular}{|c|c|c|c|c|c|c|}
\hline \multirow[t]{2}{*}{ National perinatal survey } & \multicolumn{3}{|c|}{2010} & \multicolumn{3}{|c|}{2016} \\
\hline & $\mathbf{N}$ & $\begin{array}{c}\text { Smoking prevalence } \\
(\%)\end{array}$ & $p$ value $^{a}$ & $\mathbf{N}$ & $\begin{array}{c}\text { Smoking prevalence } \\
(\%)\end{array}$ & $p$ value $^{a}$ \\
\hline Total & 13,777 & 17.0 & & 11,704 & 16.2 & \\
\hline Maternal age & 13,763 & & $<0.001$ & 11,704 & & $<0.001$ \\
\hline$<25$ years old & 2,260 & 26.2 & & 1,501 & 26.5 & \\
\hline $25-29$ & 4,604 & 17.0 & & 3,719 & 15.7 & \\
\hline $30-34$ & 4,266 & 13.9 & & 4,008 & 14.8 & \\
\hline $35+$ & 2,633 & 14.3 & & 2,476 & 13.0 & \\
\hline Country of birth & 13,689 & & $<0.001$ & 11,703 & & $<0.001$ \\
\hline France & 11,209 & 19.7 & & 9,524 & 18.5 & \\
\hline Outside France & 2,480 & 5.0 & & 2,179 & 6.1 & \\
\hline Marital status & 13,671 & & $<0.001$ & 11,680 & & $<0.001$ \\
\hline Living with a partner & 12,718 & 15.9 & & 10,701 & 15.0 & \\
\hline Single $e^{b}$ & 953 & 32.2 & & 979 & 29.4 & \\
\hline Parity at the time of pregnancy & 13,709 & & $<0.001$ & 11,700 & & $<0.001$ \\
\hline Nulliparous & 5,928 & 16.3 & & 4,963 & 15.6 & \\
\hline 1 & 4,768 & 15.3 & & 4,208 & 15.5 & \\
\hline 2 & 1,967 & 18.5 & & 1,665 & 17.0 & \\
\hline 3 or more & 1,046 & 26.4 & & 864 & 21.8 & \\
\hline Educational level & 13,642 & & $<0.001$ & 11,604 & & $<0.001$ \\
\hline None/Primary/Middle school & 3,780 & 30.1 & & 2,655 & 32.1 & \\
\hline High school & 2704 & 20.5 & & 2,514 & 19.6 & \\
\hline $1-2$ years of tertiary education & 2,939 & 13.1 & & 2,238 & 12.7 & \\
\hline $3-4$ years of tertiary education & 2,430 & 7.1 & & 2,110 & 7.8 & \\
\hline$\geq 5$ years of tertiary education & 1,789 & 4.4 & & 2,087 & 4.2 & \\
\hline Employment status at the end of pregnancy & 13,190 & & $<0.001$ & 11,445 & & $<0.001$ \\
\hline Employed & 9,290 & 14.1 & & 7,797 & 13.0 & \\
\hline Unemployed & 1,687 & 27.9 & & 1,921 & 24.6 & \\
\hline Housewife & 1,807 & 22.9 & & 1,384 & 21.2 & \\
\hline Other (including student) & 406 & 14.5 & & 343 & 14.6 & \\
\hline Average monthly household income $(€)$ & 13,286 & & $<0.001$ & 11,510 & & $<0.001$ \\
\hline$<1,000$ & 1,291 & 28.0 & & 1,101 & 26.3 & \\
\hline$[1,000-1,500]$ & 1,357 & 24.2 & & 986 & 24.7 & \\
\hline$[1,500-2000]$ & 1,964 & 22.6 & & 1,457 & 21.7 & \\
\hline [2000-3000] & 4,052 & 18.0 & & 3,189 & 18.3 & \\
\hline [3000-4000] & 2,782 & 11.0 & & 2,695 & 11.3 & \\
\hline 4,000 or more & 1,840 & 6.7 & & 2,082 & 6.5 & \\
\hline Type of social insurance cover at the beginning of pregnancy & 13,625 & & $<0.001$ & 11,690 & & $<0.001$ \\
\hline General social security & 11,765 & 15.5 & & 10,028 & 14.8 & \\
\hline Other (AME/CMU/None) ${ }^{\mathrm{c}}$ & 1,860 & 26.9 & & 1,662 & 25.1 & \\
\hline
\end{tabular}

The number of missing data varied for each characteristic.

a Pearson Chi-square test.

${ }^{b}$ single women and women not living with their partner (for 2010, it was not possible to identify women who declared being in a couple but were not living with their partner).

${ }^{c} A M E$ : state Medical assistance for undocumented migrants; CMU: health insurance for people with low or no income.

consumption rather than quit, even for heavy smokers in early pregnancy [22]. This is despite the fact that even moderate consumption is associated with low birth weight [23].

\section{Interventions in Women of Childbearing Age and Pregnant Women}

The proportions of mothers quitting smoking remained stable between 42.1 and $46.0 \%$ over the whole study period except in
1995 (when this proportion was 36.7\%), while smoking prevalence just before pregnancy varied from 16.8 to $35.8 \%$. This suggests that the prevalence of smoking during pregnancy is directly related to prevalence among women of childbearing age. The literature shows that the number of quit attempts is a positive predictor of a successful subsequent attempt [24] and that the probability of quitting during pregnancy is higher when consumption before pregnancy is low. Accordingly, any attempt to quit, even unsuccessful, in women of childbearing age, may 
TABLE 2 | Maternal characteristics associated with smoking in the 3rd trimester of pregnancy in 2010 and 2016 (multivariable analysis), data from the National Perinatal Surveys in $2010(\mathrm{~N}=12,672)$ and $2016(\mathrm{~N}=11,132)$, France.

\begin{tabular}{|c|c|c|c|c|c|c|}
\hline & \multicolumn{3}{|c|}{2010} & \multicolumn{3}{|c|}{2016} \\
\hline & Prevalence ratio & $95 \% \mathrm{Cl}$ & p value ${ }^{a}$ & Prevalence ratio & $95 \% \mathrm{Cl}$ & p value a $^{a}$ \\
\hline Maternal age (years) ${ }^{\mathrm{bc}}$ & 0.97 & [0.93-1.01] & 0.115 & 1.06 & {$[1.01-1.11]$} & 0.01 \\
\hline Country of birth ${ }^{c}$ & & & $<0.001$ & & & $<0.001$ \\
\hline Outside France & 1 & - & & 1 & - & \\
\hline France & 4.57 & {$[3.79-5.52]$} & & 3.47 & {$[2.89-4.17]$} & \\
\hline Marital status & & & $<0.001$ & & & $<0.001$ \\
\hline Living with their partner & 1 & - & & 1 & - & \\
\hline Single ${ }^{d}$ & 1.34 & {$[1.19-1.51]$} & & 1.26 & {$[1.11-1.43]$} & \\
\hline Parity at the time of pregnancy ${ }^{c}$ & & & $<0.001$ & & & 0.700 \\
\hline Nulliparous & 1 & - & & 1 & - & \\
\hline 1 & 1.01 & {$[0.93-1.11]$} & & 0.97 & {$[0.88-1.07]$} & \\
\hline 2 & 1.09 & {$[0.97-1.23]$} & & 0.93 & {$[0.81-1.06]$} & \\
\hline 3 or more & 1.38 & {$[1.20-1.59]$} & & 0.94 & {$[0.80-1.11]$} & \\
\hline Educational level & & & $<0.001$ & & & $<0.001$ \\
\hline None/primary/middle school & 4.82 & {$[3.77-6.16]$} & & 5.83 & {$[4.59-7.42]$} & \\
\hline High school & 3.62 & [2.82-4.63] & & 3.80 & {$[2.90-4.85]$} & \\
\hline $1-2^{\circ}$ years of tertiary education & 2.37 & {$[1.85-3.04]$} & & 2.50 & [1.95-3.20] & \\
\hline $3-4^{\circ}$ years of tertiary education & 1.42 & [1.08-1.85] & & 1.75 & [1.35-2.26] & \\
\hline$\geq 5^{\circ}$ years of tertiary education & 1 & - & & 1 & - & \\
\hline Employment status at end of pregnancy & & & $<0.001$ & & & $<0.001$ \\
\hline Employed & 1 & - & & 1 & - & \\
\hline Unemployment & 1.28 & {$[1.16-1.41]$} & & 1.25 & {$[1.13-1.40]$} & \\
\hline Housewife & 1.06 & {$[0.95-1.19]$} & & 1.17 & {$[1.02-1.35]$} & \\
\hline Other (including students) & 0.78 & {$[0.61-1.00]$} & & 0.98 & {$[0.76-1.24]$} & \\
\hline Average monthly household income $(€)$ & & & 0.002 & & & 0.004 \\
\hline$<1,000$ & 1.39 & {$[1.10-1.76]$} & & 1.52 & {$[1.28-1.95]$} & \\
\hline$[1,000-1,500]$ & 1.46 & {$[1.17-1.82]$} & & 1.52 & [1.21-1.93] & \\
\hline$[1,500-2000]$ & 1.46 & {$[1.18-1.81]$} & & 1.44 & {$[1.16-1.79]$} & \\
\hline [2000-3000] & 1.31 & {$[1.07-1.60]$} & & 1.38 & {$[1.14-1.70]$} & \\
\hline$[3000-4000]$ & 1.14 & {$[0.93-1.40]$} & & 1.17 & {$[0.96-1.43]$} & \\
\hline 4000 or more & 1 & - & & 1 & - & \\
\hline Type of social insurance cover at the beginning of pregnancy ${ }^{c}$ & & & $<0.001$ & & & 0.330 \\
\hline General social security & 1 & - & & 1 & - & \\
\hline Other (AME/CMU/None) ${ }^{e}$ & 1.23 & {$[1.10-1.36]$} & & 1.02 & {$[0.90-1.16]$} & \\
\hline
\end{tabular}

Data were available for $93 \%$ of the women in the sample.

a Wald test.

${ }^{b}$ calculated per 5-years increase in age.

${ }^{c}$ significant interactions: Survey year ${ }^{*}$ age $(p=0.003)$; survey year ${ }^{*}$ country of birth $(p=0.04)$; survey year ${ }^{*}$ arity $(p=0.004)$ and survey year*type of social insurance cover $(p=0.03)$. ${ }^{d}$ single women and women not living with their partner.

${ }^{e} \mathrm{AME}$ : state medical assistance for undocumented migrants; CMU: health insurance for people with low or no income.

increase the chances of success when they become pregnant [25]. Every general population-based intervention which leads to a reduction in tobacco consumption before pregnancy should also encourage smoking cessation during pregnancy.

Campaigns and interventions specifically targeting pregnant women have also been effective in increasing proportions of mothers quitting smoking during pregnancy [26]. Pregnancy is considered a favourable time for behavioral change, as parents are very receptive to prevention messages [27]. Quitting is beneficial for both the mother and the child, provided the former maintain long-term abstinence [1, 28]. However, according to one literature review, $75 \%$ of women relapse at one year after childbirth [29]. Promoting smoking cessation before pregnancy and continued abstinence in postpartum [30] would reduce the development of chronic, and therefore costly diseases both in mothers and their children [31].

\section{Socioeconomic Characteristics Associated With Smoking During Pregnancy}

The prevalence of smoking during pregnancy remained higher in women with less favourable socioeconomic characteristics in 2010 and 2016. This reflects findings in the literature [14, 15]. Health inequalities due to less favourable socioeconomic characteristics might be explained by a lower level of health literacy which leads to less knowledge and understanding of the 
risks for unborn children, of preventive measures (quitting smoking, taking folic acid, etc.) and of existing support systems [14]. These women may also consider tobacco to be an indispensable tool to manage stress [32]. Furthermore, a higher level of tobacco dependence and the fact that smoking is less frowned upon culturally in France, may also explain the greater difficulty these socially disadvantaged smokers face when attempting to quit [33]. Finally, women with a lower socioeconomic status who wish to stop smoking may need more psychological support and help from healthcare professionals because they receive less social support through advice and encouragement to quit from family and friends [34]. All these issues highlight the need for targeted actions to reduce social inequalities in terms of tobacco consumption [35]. It should be noted that, for these analysis, we hypothesized that marital status, employment status and household income did not change between the 3rd trimester of pregnancy and childbirth as the latter occurs so close to the former.

Unlike 2010, our data for 2016 highlight an increased prevalence of smoking with age in pregnant women. This is consistent with the fact that while the prevalence of daily smoking in women in the general population between both years decreased from 30.0 to $25.2 \%$ in $15-24$ year olds $(p<0.05)$, it remained stable among $25-34$ year olds (33.3\% in 2016) and $35-44$ year olds $(32.5 \%)$ [4].

The trend in the prevalence ratio according to place of birth (i.e., France versus outside France) reflects previous findings [15, 16]. In the general French population, country of birth has been associated with tobacco consumption levels [36]. Indeed, nonnative born women living in France are less likely to smoke. In our study, we found that the association between smoking during pregnancy and the place of birth varied between 2010 and 2016, with women born outside France gradually adopting French cultural habits (i.e., they tended to start smoking more). Additional analyses on the geographical area of origin and the length of time living in France [37] would make it possible to refine these results.

\section{Strengths and Limitations}

The strengths of our study include repeated surveys over a long observation period (45 years) and its exhaustiveness. With regard to the latter, almost all maternity units and all mothers agreed to participate in the NPS. We compared the number of births with birth certificates recorded by the French National office of vital statistics [38] and these numbers were very similar. Data quality was ensured by using face-to-face interviews with trained midwives. Consequently, few data were missing from the questionnaires. Furthermore, data on the characteristics of mothers, deliveries and newborns were similar to those found in the national statistics provided by hospital discharge summaries [39, 40]. The total sample of each survey is considered representative of annual births. Less than $10 \%$ of women did not answer questions about tobacco use. The stability of the design used enables trends comparisons to be made. Finally, the sample size and the broad spectrum of variables collected made it possible to analyse changes in tobacco consumption according to many maternal characteristics in 2010 and 2016.

One limitation of the study is that women who refused or could not participate in the NPS, were excluded from our analyses. These included women who had given birth to a stillborn child and those who were not interviewed because of language barriers. This may have introduced selection bias. However, stillbirths are relatively uncommon in developed countries and therefore would have had a low impact on our estimated smoking prevalences. [3]. Furthermore, language barriers may have contributed to an under-representation of mothers not born in France $(18.1 \%$ of women in our study sample versus. $22.8 \%$ in the French National office of vital statistics [38]. However, with regard to the study of risk factors associated with tobacco use, this limitation may be less relevant since women born outside France are less likely to smoke than their native-born French counterparts [41].

Another limitation in the NPS-and therefore in the present study-is that tobacco consumption is selfreported. No objective measurement is made in the NPS (e.g., using different markers such as saliva cotinine concentration [42, 43]. Higher proportions of nondisclosure of smoking by pregnant women have previously been reported [44]. Furthermore, very light smokers and those who smoke for a very brief time during pregnancy are the women most likely to underreport their tobacco consumption [45]. Nevertheless, previous findings have shown that studies which do not focus specifically on tobacco-like the NPS-described lower underreporting. [46, 47]. The NPS aim to characterize all indicators related to pregnancy in France and not just smoking behaviour. As a result, only a limited number of questions were asked about this specific topic. For instance, we had no information about the smoking status of partners, the exact date of smoking cessation during pregnancy, or the motivations that drove women to quit or reduce consumption.

\section{Conclusions and Implications for Policy and Practice}

In France, tobacco consumption before and during pregnancy remained high over the study period. Although the amount of tobacco consumed decreased from 1995 onward, the proportions of cessation during pregnancy remained stable from 1972 onward. Cessation remains a major public health issue [23]. In order to help reduce the burden of smoking during pregnancy, campaigns and practical support for the general population are needed. These must be complemented by more specific actions targeting pregnant women, in particular women at a greater risk of continuing to smoke during pregnancy. Providing initial and continuous training to healthcare providers may also help integrate smoking cessation - not only reduction-into routine prenatal care. To help evaluate and guide such policies, it is also important to continue monitoring the trends in tobacco smoking in pregnant women and the associated risk factors, especially in France where several ambitious tobacco control measures have been implemented since 2016 . 


\section{DATA AVAILABILITY STATEMENT}

The data analyzed in this study is subject to the following licenses/restrictions: The data that support the findings of this study are not publicly available. A reasonable request must be submitted to Obstetrical, Perinatal and Pediatric Epidemiology Research Team EPOPé, INSERM U1153 and approved by the French Data Protection Authority (CNIL). Requests to access these datasets should be directed to epope@inserm.fr.

\section{ETHICS STATEMENT}

The surveys were approved by the National Council on Statistical Information (Comité du Label, authorization 2016X703SA for 2016), the French Data Protection Authority (CNIL, authorization 915197 for 2016), and the INSERM ethics committee (authorization IRB00003888 no. 14-191 for 2016). Written informed consent for participation was not required for this study in accordance with the national legislation and the institutional requirements.

\section{REFERENCES}

1. West, R. Tobacco smoking: health impact, prevalence, correlates and interventions. Psychol Health (2017). 32(8):1018-1036. doi:10.1080/ 08870446.2017.1325890

2. Popova, S, Lange, S, Probst, C, Parunashvili, N., and Rehm, J. Prevalence of alcohol consumption during pregnancy and fetal alcohol spectrum disorders among the general and Aboriginal populations in Canada and the United States. Eur J Med Genet (2017). 60(1):32-48. doi:10.1016/j.ejmg.2016.09.010

3. Euro-Peristat Project. European perinatal health report. Core indicators of the health and care of pregnant women and babies in Europe in 2015 (2018).

4. Pasquereau, A, Gautier, A, Andler, R, Guignard, R, Richard, JB, Nguyen, TV, et al. Tabac et e-cigarette en France : niveaux d'usage d'après les premiers résultats du Baromètre santé 2016. Bull Epidémiol Hebd (2017). (12) 214-222.

5. Blondel, B, Coulm, B, Bonnet, C, Goffinet, F, and Le Ray, C. Trends in perinatal health in metropolitan France from 1995 to 2016: results from the French national perinatal surveys. J Gynecol Obstet Hum Reprod (2017). 46(10): 701-713. doi:10.1016/j.jogoh.2017.09.002

6. Lelong, N, Blondel, B, and Kaminski, M. Évolution de la consommation de tabac des femmes pendant la grossesse en France de 1972 à 2003. J de Gynécologie Obstétrique et Biologie de la Reprod (2011). 40(1):42-49. doi:10.1016/j.jgyn. 2010.07.007

7. Passmore, E, McGuire, R, Correll, P, and Bentley, J. Demographic factors associated with smoking cessation during pregnancy in New South Wales, Australia, 2000-2011. BMC Public Health (2015). 15. doi:10.1186/s12889-015$1725-2$

8. Tong, VT, Dietz, PM, Morrow, B, D’Angelo, DV, Farr, SL, Rockhill, KM, et al. Trends in smoking before, during, and after pregnancy--pregnancy risk assessment monitoring system, United States, 40 sites, 2000-2010. MMWR Surveill Summ (2013). 62(6):1-19.

9. Grangé, G, Berlin, I, Bretelle, F, Bertholdt, C, Berveiller, P, DiGuisto, C, et al. Smoking and smoking cessation in pregnancy. Synthesis of a systematic review. J Gynecol Obstet Hum. Reprod. (2020). 49:101847. doi:10.1016/j.jogoh.2020. 101847

10. National Center for Chronic Disease Prevention and Health Promotion (US) Office on Smoking and Health. Reports of the surgeon general. The Health consequences of smoking-50 years of progress: A Report of the surgeon general. Atlanta (GA): Centers for Disease Control and Prevention (US) (2014).

\section{AUTHOR CONTRIBUTIONS}

VD realized statistical analysis. VD and NR were major contributors in interpretation of results and writing the manuscript. $\mathrm{BB}, \mathrm{CB}$ and $\mathrm{MC}$ contributed to the study design and datamanagement. All authors have made a substantial contribution to the writing and intellectual content of the article. All authors read and approved the final manuscript for submission to International Journal Public Health.

\section{CONFLICT OF INTEREST}

The authors declare that the research was conducted in the absence of any commercial or financial relationships that could be construed as a potential conflict of interest.

\section{SUPPLEMENTARY MATERIAL}

The Supplementary Material for this article can be found online at: https://www.ssph-journal.org/articles/10.3389/ijph.2021.602873/ full\#supplementary-material.

11. Clifford, A, Lang, L, and Chen, R. Effects of maternal cigarette smoking during pregnancy on cognitive parameters of children and young adults: a literature review. Neurotoxicol Teratol (2012). 34(6):560-570. doi:10.1016/j.ntt.2012.09.004

12. Cornelius, MD, Goldschmidt, L, and Day, NL. Prenatal cigarette smoking: long-term effects on young adult behavior problems and smoking behavior. Neurotoxicol Teratol (2012). 34(6):554-559. doi:10.1016/j.ntt.2012.09.003

13. Schneider, S, and Schütz, J. Who smokes during pregnancy? A systematic literature review of population-based surveys conducted in developed countries between 1997 and 2006. Eur J Contraception Reprod Health Care (2008). 13(2):138-147. doi:10.1080/13625180802027993

14. Smedberg, J, Lupattelli, A, Mardby, AC, and Nordeng, H. Characteristics of women who continue smoking during pregnancy: a cross-sectional study of pregnant women and new mothers in 15 European countries. BMC Pregnancy Childbirth (2014). 14:213. doi:10.1186/1471-2393-14-213

15. Azagba, S, Manzione, L, Shan, L, and King, J. Trends in smoking during pregnancy by socioeconomic characteristics in the United States, 2010-2017. BMC Pregnancy Childbirth (2020). 20(1):52. doi:10.1186/s12884-020-2748-y

16. Grøtvedt, L, Kvalvik, LG, Grøholt, EK, Akerkar, R, and Egeland, GM. Development of social and demographic differences in maternal smoking between 1999 and 2014 in Norway. Nicotine Tob Res (2017). 19(5):539-546. doi:10.1093/ntr/ntw313

17. Blondel, B, Breart, G, Du Mazaubrun, C, Badeyan, G, Wcislo, M, Lordier, A, et al. La situation périnatale en France: évolution entre 1981 et 1995. J Gynecol Obstet Biol Reprod (Paris) (1996). 26(8):770-780. doi:10.1016/S0368-2315(06)76409-2

18. Blondel, B, and Zuber, MC. Marital status and cohabitation during pregnancy: relationship with social conditions, antenatal care and pregnancy outcome in France. Paediatr Perinat Epidemiol (1988). 2(2):125-137. doi:10.1111/j.13653016.1988.tb00192.x

19. Rumeau-Rouquette, C, Du Mazaubrun, C, and Rabarison, Y. Naître en France, 10 ans d'évolution. Paris, Fraence: Inserm-Doin (1984).

20. Barros, AJ, and Hirakata, VN. Alternatives for logistic regression in crosssectional studies: an empirical comparison of models that directly estimate the prevalence ratio. BMC Med Res Methodol (2003). 3:21. doi:10.1186/1471-22883-21

21. Schneider, S, Huy, C, Schütz, J, and Diehl, K. Smoking cessation during pregnancy: a systematic literature review. Drug Alcohol Rev (2010). 29(1): 81-90. doi:10.1111/j.1465-3362.2009.00098.x

22. Andler, R, Cogordan, C, Pasquereau, A, Buyck, JF, and Nguyen-Thanh, V. The practices of French general practitioners regarding screening and counselling 
pregnant women for tobacco smoking and alcohol drinking. Int J Public Health (2018). 63(5):631-640. doi:10.1007/s00038-018-1103-9

23. Berlin, I, Golmard, JL, Jacob, N, Tanguy, ML, and Heishman, SJ. Cigarette Smoking during pregnancy: do complete abstinence and low level cigarette smoking have similar impact on birth weight? Nicotine Tob Res (2017). 19(5): 518-524. doi:10.1093/ntr/ntx033

24. Hagimoto, A, Nakamura, M, Morita, T, Masui, S, and Oshima, A. Smoking cessation patterns and predictors of quitting smoking among the Japanese general population: a 1-year follow-up study. Addiction (2010). 105(1): 164-173. doi:10.1111/j.1360-0443.2009.02735.x

25. Chaiton, M, Diemert, L, Cohen, JE, Bondy, SJ, Selby, P, Philipneri, A, et al. Estimating the number of quit attempts it takes to quit smoking successfully in a longitudinal cohort of smokers. BMJ Open (2016). 6(6):e011045. doi:10.1136/ bmjopen-2016-011045

26. Chamberlain, C, O'Mara-Eves, A, Porter, J, Coleman, T, Perlen, SM, Thomas, $\mathrm{J}$, et al. Psychosocial interventions for supporting women to stop smoking in pregnancy. Cochrane Database Syst Rev (2017). 2:CD001055. doi:10.1002/ 14651858.CD001055.pub5

27. Crozier, SR, Robinson, SM, Borland, SE, Godfrey, KM, Cooper, C, and Inskip, HM. Do women change their health behaviours in pregnancy? Findings from the southampton women's survey. Paediatr Perinat Epidemiol (2009). 23(5): 446-453. doi:10.1111/j.1365-3016.2009.01036.x

28. England, LJ, Kendrick, JS, Wilson, HG, Merritt, RK, Garguillo, PM, and Christine Zahniser, S. Effects of smoking reduction during pregnancy on the birth weight of term infants. Am J Epidemiol (2001). 154(8):694-701. doi:10.1093/aje/154.8.694

29. Orton, S, Coleman, T, Coleman-Haynes, T, and Ussher, M. Predictors of postpartum return to smoking: a systematic review. Nicotine Tob Res (2018). 20(6):665-673. doi:10.1093/ntr/ntx163

30. Coleman-Cowger, VH. Smoking cessation intervention for pregnant women: a call for extension to the postpartum period. Matern Child Health J (2012). 16(5):937-940. doi:10.1007/s10995-011-0837-2

31. Toll, BA, Rojewski, AM, Duncan, LR, Latimer-Cheung, AE, Fucito, LM, Boyer, $J \mathrm{~L}$, et al. "Quitting smoking will benefit your health": the evolution of clinician messaging to encourage tobacco cessation. Clin Cancer Res (2014). 20(2): 301-309. doi:10.1158/1078-0432.ccr-13-2261

32. Dejin-Karlsson, E, Hanson, BS, Ostergren, PO, Ranstam, J, Isacsson, SO, and Sjoberg, NO. Psychosocial resources and persistent smoking in early pregnancy-a population study of women in their first pregnancy in Sweden. J Epidemiol Community Health (1996). 50(1):33-39. doi:10.1136/jech.50.1.33

33. Kotz, D, and West, R. Explaining the social gradient in smoking cessation: it's not in the trying, but in the succeeding. Tob Control (2009). 18(1):43-46. doi:10.1136/tc.2008.025981

34. Edwards, R, McElduff, P, Jenner, D, F Heller, R, and Langley, J. Smoking, smoking cessation, and use of smoking cessation aids and support services in South Derbyshire, England. Public Health (2007). 121(5):321-332. doi:10. 1016/j.puhe.2006.11.002

35. Brown, T, Platt, S, and Amos, A. Equity impact of European individual-level smoking cessation interventions to reduce smoking in adults: a systematic review. Eur J Public Health (2014). 24(4):551-556. doi:10.1093/eurpub/cku065
36. Khlat, M, Legleye, S, and Bricard, D. Migration-related changes in smoking among non-Western immigrants in France. Eur J Public Health (2018). 29: 453-457. doi:10.1093/eurpub/cky230

38. INSEE. Les naissances en 2016. Paris, Franch: INSEE Résultats (2017).

37. Urquia, ML, O'Campo, PJ, and Heaman, MI. Revisiting the immigrant paradox in reproductive health: the roles of duration of residence and ethnicity. Soc Sci Med (2012). 74(10):1610-1621. doi:10.1016/j.socscimed. 2012.02.013

39. Coulm, B, Bonnet, C, and Blondel, B. French national perinatal survey 2016. Paris, Franch: INSERM (2017).

40. Quantin, C, Cottenet, J, Vuagnat, A, Prunet, C, Mouquet, MC, Fresson, J, et al. Qualité des données périnatales issues du PMSI: comparaison avec l'état civil et l'enquête nationale périnatale 2010. J de Gynécologie Obstétrique et Biologie de la Reprod (2014). 43(9):680-690. doi:10.1016/j.jgyn.2013. 09.004

41. Melchior, M, Chollet, A, Glangeaud-Freudenthal, N, Saurel-Cubizolles, MJ, Dufourg, MN, van der Waerden, J, et al. Tobacco and alcohol use in pregnancy in France: The role of migrant status. Addict Behaviors (2015). 51:65-71. doi:10.1016/j.addbeh.2015.07.015

42. Boyd, NR, Windsor, RA, Perkins, LL, and Lowe, JB. Quality of measurement of smoking status by self-report and saliva cotinine among pregnant women. Matern Child Health J (1998). 2(2):77-83. doi:10.1023/a:1022936705438

43. Hegaard, HK, Kjærgaard, H, Møller, LF, Wachmann, H, and Ottesen, B. Determination of a saliva cotinine cut-off to distinguish pregnant smokers from pregnant non-smokers. Acta Obstet Gynecol Scand (2007). 86(4): 401-406. doi:10.1080/00016340601147517

44. Dietz, PM, Homa, D, England, LJ, Burley, K, Tong, VT, Dube, SR, et al. Estimates of nondisclosure of cigarette smoking among pregnant and nonpregnant women of reproductive age in the United States. $A m$ J Epidemiol (2011). 173(3):355-359. doi:10.1093/aje/kwq381

45. England, L, Grauman, A, Qian, C, Wilkins, D, Schisterman, E, Yu, K, et al. Misclassification of maternal smoking status and its effects on an epidemiologic study of pregnancy outcomes. Nicotine Tob Res. (2007). 9(10):1005-1013. doi:10.1080/14622200701491255

46. Klebanoff, MA, Levine, RJ, Morris, CD, Hauth, JC, Sibai, BM, Ben Curetevine, $\mathrm{L}$, et al. Accuracy of self-reported cigarette smoking among pregnant women in the 1990s. Paediatr Perinat Epidemiol (2001). 15(2):140-143. doi:10.1046/j. 1365-3016.2001.00321.x

47. Lindqvist, R, Lendahls, L, Tollbom, Ö, ÅBerg, H, and Håkansson, A. Smoking during pregnancy: comparison of self-reports and cotinine levels in 496 women. Acta Obstet Gynecol Scand (2002). 81(3):240-244. doi:10.1034/j. 1600-0412.2002.810309.x

Copyright (๑) 2021 Demiguel, Blondel, Bonnet, Nguyen-Thanh, Saurel-Cubizolles and Regnault. This is an open-access article distributed under the terms of the Creative Commons Attribution License (CC BY). The use, distribution or reproduction in other forums is permitted, provided the original author(s) and the copyright owner(s) are credited and that the original publication in this journal is cited, in accordance with accepted academic practice. No use, distribution or reproduction is permitted which does not comply with these terms. 